\title{
Impact of a motorcycle on cyclist aerodynamic drag in parallel and staggered arrangements
}

\author{
Bert Blocken $^{1,2}$ (D) Stefanie Gillmeier ${ }^{1} \cdot$ Fabio Malizia $^{1,2} \cdot$ Thijs van Druenen $^{1}$
}

Accepted: 23 March 2021 / Published online: 7 April 2021

(c) The Author(s) 2021

\begin{abstract}
Cycling races contain a multitude of motorcycles for various activities including television broadcasting. During parts of the race, these motorcycles can ride in close proximity of cyclists. Earlier studies focused on the impact of a nearby motorcycle on cyclist drag for in-line arrangements. It was shown that not only a motorcycle in front of a cyclist but also a motorcycle closely behind a cyclist can substantially reduce cyclist drag. However, there appears to be no information in the scientific literature about the impact of the motorcycle on cyclist drag for parallel and staggered arrangements. This paper presents wind tunnel measurements of cyclist drag for 32 different parallel and staggered cyclist-motorcycle arrangements. It is shown that the parallel arrangement leads to a drag increase for the cyclist, in the range of 5 to about $10 \%$ for a lateral distance of 2 to $1 \mathrm{~m}$. The staggered arrangement can lead to either a drag increase or a drag decrease, where the latter is about $2 \%$ for most positions analyzed. For one of the parallel arrangements, computational fluid dynamics simulations were performed to provide insight into the reasons for the drag increase. A cyclist power model was used to convert the drag changes into potential time gains or losses. Compared to a lone cyclist riding at a speed of $46.8 \mathrm{~km} / \mathrm{h}(13 \mathrm{~m} / \mathrm{s})$ on level road in calm weather, the time loss by a drag increase of $10 \%, 4 \%$ and $-2 \%$ was $2.16,0.76 \mathrm{~s}$ and $-0.80 \mathrm{~s}$ per $\mathrm{km}$, respectively. These time differences are large enough to influence the outcome of cycling races.
\end{abstract}

Keywords Computational fluid dynamics · Wind tunnel · Aerodynamic cyclist drag · Cycling aerodynamics · Motorbike

\section{Introduction}

The aerodynamic resistance or drag of a cyclist is about $90 \%$ of the total resistance at racing speeds of about $40 \mathrm{~km} / \mathrm{h}$ $(11.1 \mathrm{~m} / \mathrm{s})$ [1-3]. Much scientific research in professional cycling is therefore focused on the reduction of cyclist drag (e.g., $[4,5])$. Cycling races contain a multitude of cars and motorcycles. The motorcycles can be neutral support, commissaire, traffic manager, information, doctor, police or press motorcycles, where the latter can be camera, sound or photographer motorcycles. The motorcycles are allowed to maneuver in the proximity of the cyclists when filming

Bert Blocken

b.j.e.blocken@tue.nl

1 Building Physics and Services, Department of the Built Environment, Eindhoven University of Technology, P.O. box 513, $5600 \mathrm{MB}$ Eindhoven, the Netherlands

2 Building Physics and Sustainable Design, Department of Civil Engineering, KU Leuven, Kasteelpark Arenberg 40 bus 2447, 3001 Leuven, Belgium or recording. Filming is only forbidden in the last $500 \mathrm{~m}$ of the race. Previous research analyzed the impact of nearby cars and motorcycles on cyclist drag. Blocken and Toparlar [6] determined that a car behind a cyclist can yield a drag reduction for the cyclist of $3.7,1.4$ and $0.2 \%$ for separation distances of 3, 5 and $10 \mathrm{~m}$, respectively. Blocken et al. [7] demonstrated that a motorcycle following a cyclist can provide a drag reduction for the cyclist of $3.8,0.3$ and $0.1 \%$ for separation distances of 1,5 and $10 \mathrm{~m}$, respectively. More recently, Blocken et al. [8] focused on quantifying the aerodynamic benefits for a cyclist by drafting behind a motorcycle. While it was well known in professional cycling that drafting behind a motorcycle can yield large drag reductions, the actual values had not yet been determined. It was shown that drafting at 2.64, 10, 30 and $50 \mathrm{~m}$ behind a motorcycle could yield drag reductions of $48,23,12$ and $7 \%$, respectively.

At many occasions during a race, cyclists and motorcycles are not riding in line, but in parallel (Fig. 1a) or staggered arrangement (Fig. 1b-d). The pertaining guidelines of the International Cycling Union (UCI) for "vehicle circulation in 

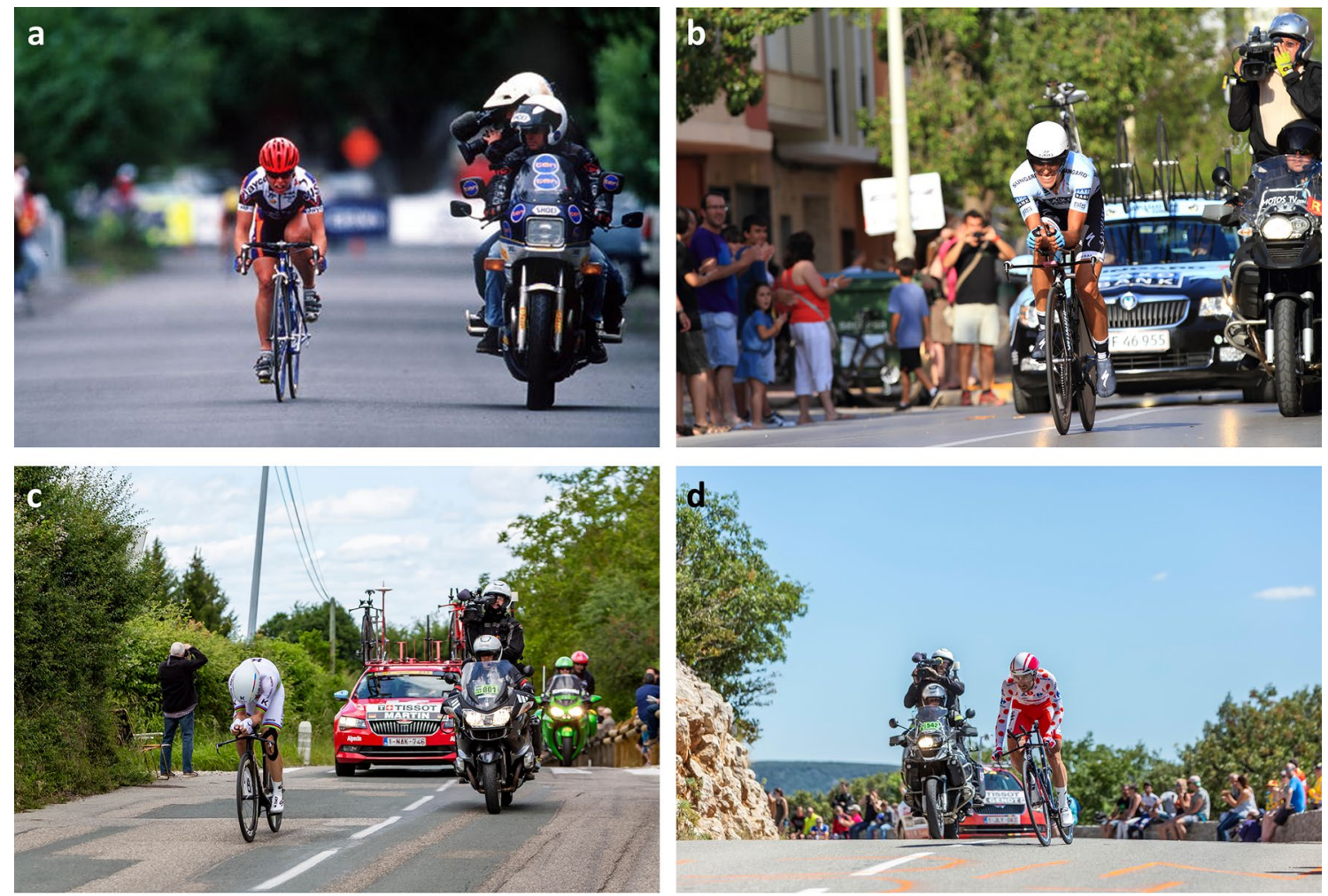

Fig. 1 Photos of cyclist and motorcycle in parallel or staggered arrangement: (a) parallel; (b-d) staggered. (Fig. sources: a: mark Dadswell/ Getty Images; b-d: Radu Razvan/Shutterstock.com; all photos reproduced with permission)

the race convoy" only stipulate when and which motorcycles can enter the gaps between breakaway riders and the following riders in terms of time differences, which can be 15, 30, 60 and $90 \mathrm{~s}$ [9]. The larger the time differences, the more motorcycles can enter the gap. However, the UCI guidelines do not specify what distance should be kept between the motorcycles and the cyclists [9].

To the best of our knowledge, there is no information in the scientific literature about the impact of a nearby motorcycle on cyclist drag for parallel and staggered arrangements. Some earlier studies assessed the aerodynamic interaction between two cyclists in parallel and staggered arrangement. Zdravkovich et al. [10] performed wind tunnel tests with real riders in a variety of in-line and slightly staggered arrangements. The slightly staggered arrangements were studied because they were considered safer as they reduce the chance of catching the rear wheel of the lead cyclist and provide a less obstructed view of the road ahead. It was found that the beneficial drafting effect was abruptly reduced for both a 0.2 and $0.3 \mathrm{~m}$ stagger. Barry et al. [11] conducted wind tunnel experiments on a real cyclist together with a manikin in both in-line and so-called overtaking positions, including a parallel arrangement. They described the variation of the drag during the overtaking process. As the overtaking rider moved forward, the leading rider drag increased. When both riders were side by side, they both had a drag above that of an isolated rider. As the overtaking continued, a drag decrease occurred for both riders. For the side-by-side arrangement with a minimum lateral separation distance of $0.5 \mathrm{~m}$ between the two rider centerlines, the drag increase was $6 \%$. This increase became negligible beyond $1.5 \mathrm{~m}$ lateral separation. More recently, Gromke and Ruck [12] performed a field measurement campaign assessing the lateral loads on cyclist dummies of an adult and a child being overtaken by a station wagon. Different bicycle types were considered and distinct lateral load phases were observed: a pressure phase with a lateral load acting to push the cyclist away followed by a suction phase with a lateral load acting to pull the cyclist towards the vehicle. They did not provide information on the aerodynamic drag in the riding direction, which is the focus of the present paper.

These studies on the aerodynamic effect of a nearby cyclist or a car on a cyclist provide some trends that could be expected to hold also for a cyclist and a nearby motorcycle. However, the streamwise and lateral distances between two drafting and overtaking cyclists are typically much smaller than those occurring between a cyclist and a motorcycle, necessitating a separate study for the latter. Therefore, this paper presents a series of wind tunnel measurements and some computational fluid dynamics (CFD) simulations to

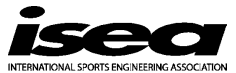


analyze the impact of a nearby motorcycle on cyclist drag for parallel and staggered arrangements.

\section{Wind tunnel experiments}

\subsection{Experimental set-up}

The wind tunnel experiments (WT) were performed on quarter-scale models of a cyclist and a motorcycle carrying two people (Fig. 2a-d). Details of the models and the wind tunnel can be found in $[8,13]$. The WT set-up was described in an earlier publication [8] and the description is summarized here for completeness. The models were placed on an elevated sharp-edged smooth horizontal plate to limit boundary layer development. (Fig. 2e-f). The blockage ratio of the set-up was about $2 \%$, which is below the recommended maximum of 5\% for WT tests [14]. The measured longitudinal turbulence intensity at the model position was $0.3 \%$. The cyclist was positioned on a force sensor that was situated below the plate. The force sensor was designed and manufactured in house specifically for high-accuracy quarter-scale cyclist WT tests [15] with an accuracy of $0.001 \mathrm{~N}$. Data were sampled at $10 \mathrm{~Hz}$ for $60 \mathrm{~s}$. Tests were performed at wind speeds of 15, 20, 25 and $30 \mathrm{~m} / \mathrm{s}$ to detect Reynolds number independence, which was noted above $20 \mathrm{~m} / \mathrm{s}$. The Reynolds number independent results are reported in the results section. It was assumed that there was no crosswind, no head wind and no tail wind, therefore the WT speed represented the riding velocity. a
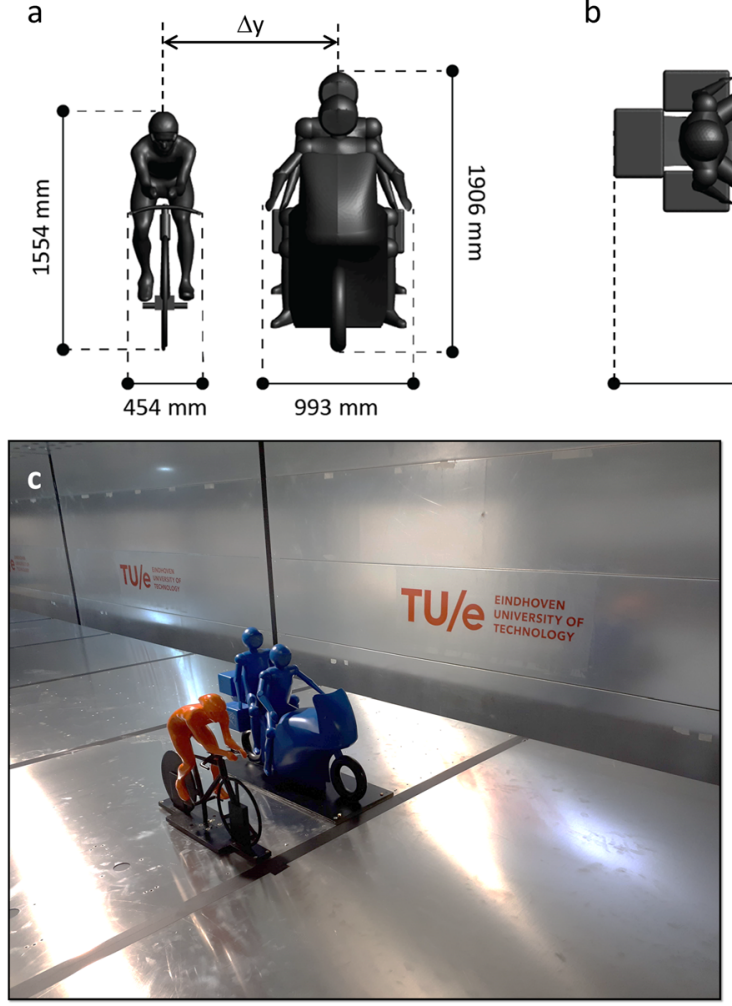

e

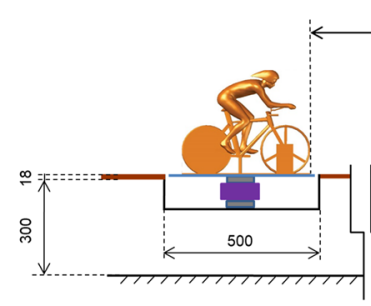

b
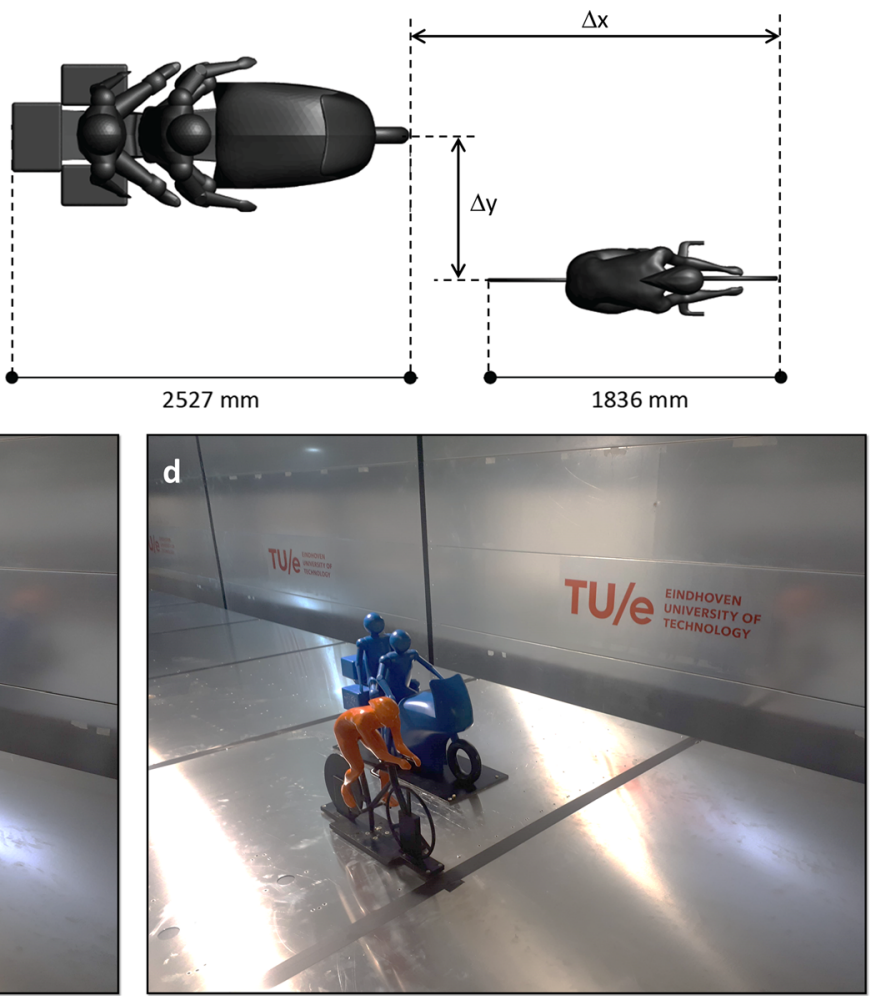

f

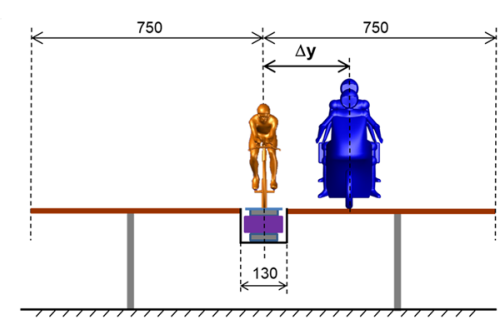

Fig. 2 a, b Dimensions (full-scale equivalent) of the quarter-scale models. c, d Photos of wind tunnel set-up: cyclist and motorcycle in (c) parallel or (d) staggered position. e, f Cyclist and motorcycle in staggered position on eleated sharp-edged plate with reduced-scale dimensions in mm: (e) Side view; (f) Front view 
Two sets of cyclist-motorcycle arrangements were tested. All distances below are reported in full-scale values. The first set of 27 arrangements had the motorcycle at a lateral distance $\Delta \mathrm{y}=1.3 \mathrm{~m}$ and a streamwise distance $\Delta \mathrm{x}$ ranging from $+7.2 \mathrm{~m}$ (cyclist downstream of motorcycle) to $-4.8 \mathrm{~m}$ (cyclist upstream of motorcycle) in steps of $0.48 \mathrm{~m}$ (Fig. 3). The second set of five arrangements had the cyclist and motorcycle parallel (both front wheel ends at same streamwise coordinate) and $\Delta \mathrm{y}$ ranging from 1 to $2 \mathrm{~m}$ in steps of $0.25 \mathrm{~m}$ (Fig. 4). To assess the repeatability of the experimentally obtained drag values, the isolated cyclist was tested five times throughout the measurement campaign, by detaching and remounting the model on the force sensor. Based on these measurements, the repeatability of the obtained drag values was found to be $0.7-0.9 \%$, which corresponded to drag differences of about $0.3 \mathrm{~N}$ for the isolated cyclist. All drag measurements were corrected to match the following reference values: $101,325 \mathrm{~Pa}$ (standard atmosphere), $15^{\circ} \mathrm{C}$, $15 \mathrm{~m} / \mathrm{s}$ (a top time trial speed) and full geometrical scale.

\subsection{Results}

Figure 3 presents the results for the first WT set. The parallel position yielded an increase of cyclist drag of about $7.5 \%$. This drag increase lowered as the cyclist and motorcycle move farther apart in the streamwise direction. For the cyclist upstream of the motorcycle, at $\Delta x=-1.44 \mathrm{~m}$, the drag change was nearly zero and switched sign. For larger distances, the cyclist experienced a drag decrease until about $\Delta \mathrm{x}=-4.8 \mathrm{~m}$. This drag decrease was attributed to the so-called subsonic upstream disturbance similar to earlier studies $[6,7,16]$. This refers to the fact that the

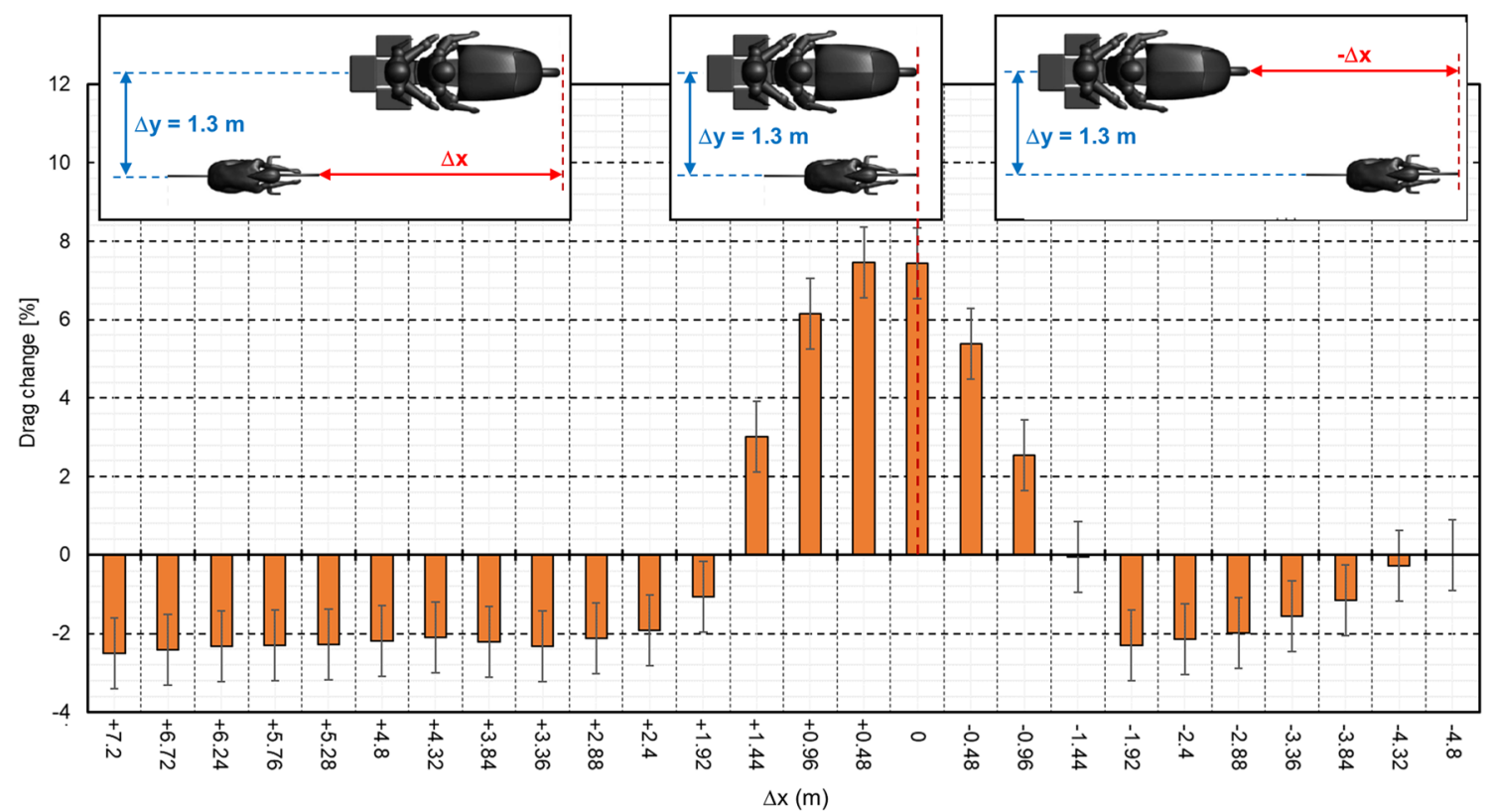

Fig. 3 Drag change in percentage for cyclist due to proximity of motorcycle, for fixed lateral distance $\Delta y=1.3 \mathrm{~m}$ (full scale) and varying streamwise distance $\Delta \mathrm{x}$ (full scale)

Fig. 4 Drag increase in percentage for cyclist due to proximity of motorcycle in parallel arrangement for varying lateral distance $\Delta \mathrm{y}$ (full scale)
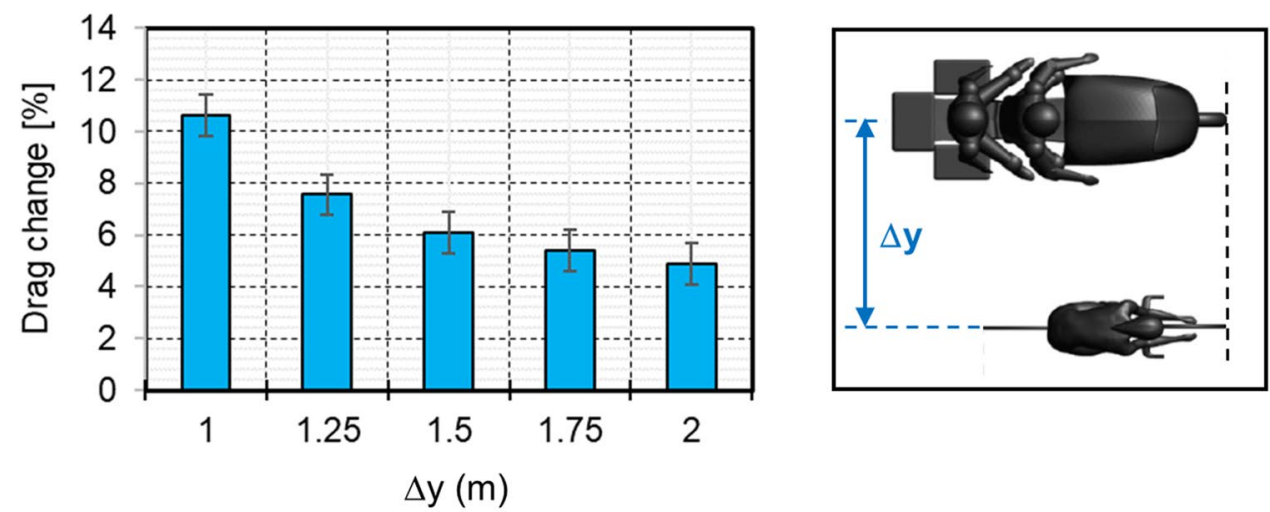

$\Delta y(m)$ 
motorcycle - just like the cyclist - does not only disturb the flow downstream but also upstream of it. For the cyclist downstream of the motorcycle, a drag decrease occurred from about $\Delta \mathrm{x}=+1.92 \mathrm{~m}$ to at least $+7.2 \mathrm{~m}$. This could be attributed to the partial presence of the cyclist in the wake behind the motorcycle. Figure 4 shows the results for the second WT set. The drag increase of the parallel arrangement gradually became less pronounced as $\Delta \mathrm{y}$ increased, but still amounted to $5 \%$ at $\Delta y=2 \mathrm{~m}$. To provide further insight in the reasons of these drag differences, some CFD simulations were performed.

\section{CFD simulations}

\subsection{Computational settings and parameters}

The CFD simulations were performed at full scale. The cyclist and motorcycle geometry were identical to those of the WT models apart from the WT model bottom plate, the vertical reinforcement bars in the cycling wheels (Fig. 2c-d) and the geometrical scale (1:1 versus 1:4). $\Delta \mathrm{y}$ was $1.3 \mathrm{~m}$. The rectangular computational domain had dimensions length $\mathrm{x}$ width $\mathrm{x}$ height $=60 \times 32 \times 24 \mathrm{~m}^{3}$. The blockage ratio was about $0.1 \%$, which is below the recommended maximum of $3 \%$ for CFD simulations [17-20].

The computational grids were hybrid hexahedral-tetrahedral grids based on grid convergence analysis (not reported here) and on grid generation guidelines [16-24]. They had a wall-adjacent cell size of $20 \mu \mathrm{m}(=0.02 \mathrm{~mm})$ and 40 layers of prismatic cells near the cyclist and motorcycle surfaces to accurately resolve the thin boundary layer including the laminar sublayer (Fig. 5). The dimensionless wall unit $y^{*}$ had values that were generally below one and always below five. The cell size in the area between motorcycle and cyclist was $0.03 \mathrm{~m}$. Figure 5 shows the grid resolution on the surface of the cyclist, motorcycle and in the vertical plane through the cyclist. The total cell count was $53.2 \times 10^{6}$.

The computational settings are identical to those in [8] and are summarized here for completeness. At the inlet, a uniform velocity of $15 \mathrm{~m} / \mathrm{s}$ was imposed that represented the riding velocity. As in the WT tests, it was assumed that there was no crosswind, no head wind and no tail wind. The inlet turbulence intensity was set to $0.5 \%$ to obtain the same approach-flow value of $0.3 \%$ in the region directly upstream of the motorcycle as in the wind tunnel. This was required because the turbulence intensity decayed from 0.5 to $0.3 \%$ from the inlet of the computational domain to the position of the motorcycle model. At the outlet, zero static gauge pressure was set. The bottom, side and top surfaces of the domain were slip walls. The surfaces of the motorcycle and cyclist were no-slip walls, where the cyclist body and the motorcycle had a surface roughness with equivalent sand-grain roughness height $k_{S}=0.1 \mathrm{~mm}$ and the bicycle $k_{S}=0 \mathrm{~mm}$.

Scale Adaptive Simulations (SAS) [26] were performed involving the Shear Stress Transport (SST) k- $\omega$ model [25] with curvature correction. Pressure-velocity coupling was
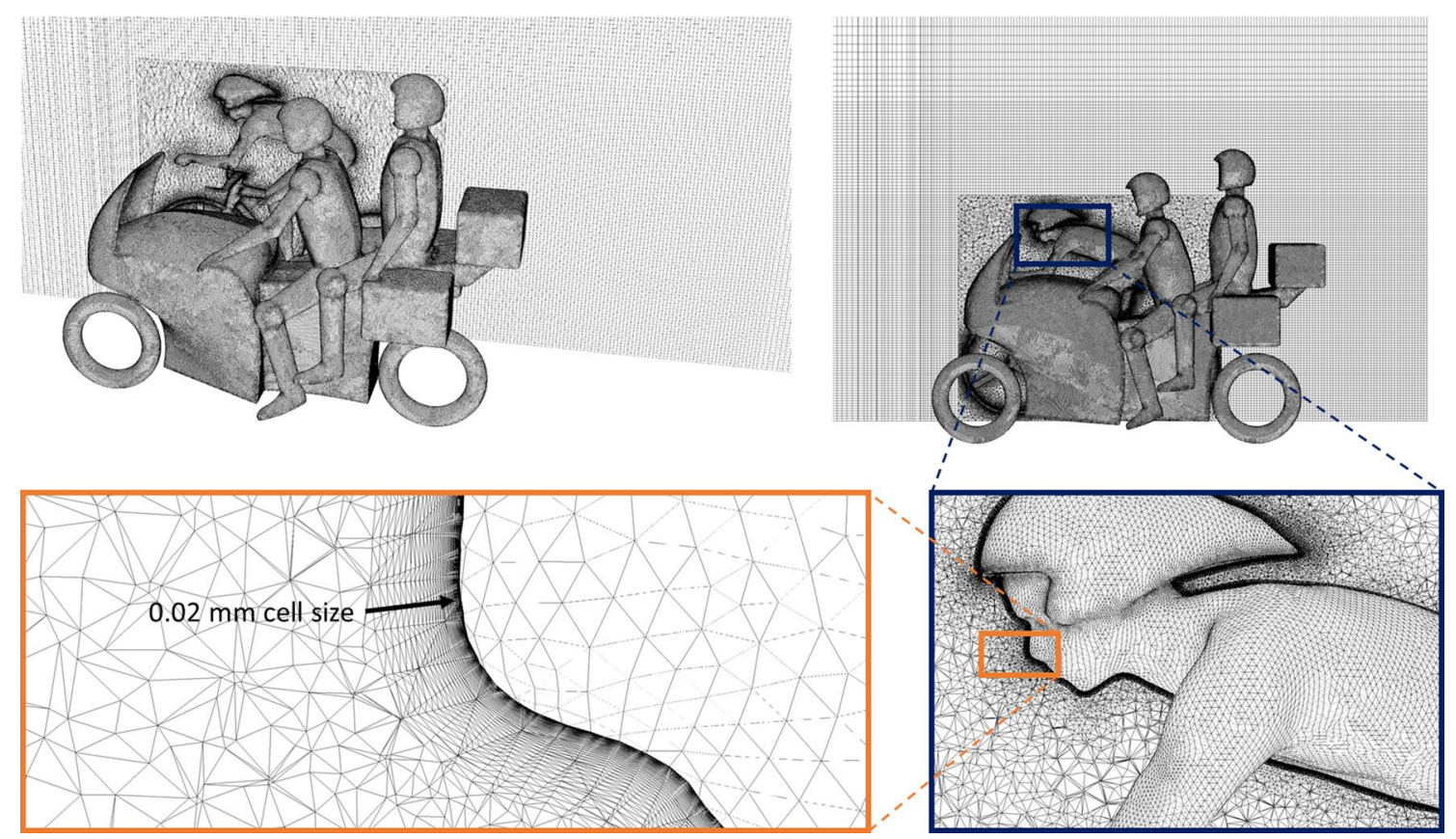

Fig. 5 Computational grid on motorcycle and cyclist surfaces and in vertical centerplane for streamwise distance $\Delta x=0$ and lateral distance $\Delta \mathrm{y}=1.3 \mathrm{~m}$. Minimum cell size: $0.02 \mathrm{~mm}$ (full scale). Total cell count is $53.2 \mathrm{million}$ 
performed by the PISO algorithm. Pressure interpolation was second order, gradient interpolation was conducted with the Green-Gauss node-based scheme. Bounded central differencing was used for the momentum equations and second-order discretization for the turbulence model equations. Time discretization was bounded second-order implicit. The simulations were performed with the commercial CFD code Ansys Fluent 16.1 [27]. The time step of $0.002 \mathrm{~s}$ was selected such that the Courant-Friedrichs-Lewy (CFL) number was equal to unity or below unity in the area between the motorcycle and the cyclist. A time step convergence analysis confirmed the suitability of this time step [8]. The number of time steps required to obtain a constant moving average of the sampled drag values was 8000 .

\subsection{Results}

The computed isolated cyclist drag area $\left(\mathrm{C}_{\mathrm{d}} \mathrm{A}\right)$ was 0.231 $\mathrm{m}^{2}$ while that of the cyclist in parallel arrangement with the motorcycle was $0.248 \mathrm{~m}^{2}$, yielding about $7.5 \%$ drag increase, in line with the WT result at $\Delta x=0$ (Fig. 3).

Figure 6 presents contours of air speed in a horizontal plane at $0.8 \mathrm{~m}$ above ground, for the parallel arrangement compared with the isolated cyclist. Figure $6 a, b$ shows the time-averaged results, while Fig. $6 c-j$ shows instantaneous results at time intervals of $0.12 \mathrm{~s}$. The presence of the motorcycle increased the size of the high-speed areas (red color) wrapping around the cyclist's waist. These areas partly interacted with similar areas around the front part of the motorcycle, yielding a high-speed jet in between the cyclist and motorcycle (see Fig. 6a). Due to the presence of the motorcycle, the velocity in the wake behind the cyclist increased, the wake behind the cyclist widened and slightly curved towards the wake behind the motorcycle.

Figure 7 depicts contours of pressure coefficient $\mathrm{C}_{\mathrm{p}}$ in a horizontal plane at $0.8 \mathrm{~m}$ above ground. For the isolated cyclist, a clear over-pressure area (red/orange) in front and under-pressure areas (blue) on the side and behind the cyclist body were present, where the latter was distorted over time by periodic vortex shedding. For the parallel arrangement, the large over-pressure area in front of the motorcycle partly merged with that in front of the cyclist. Also the large underpressure area behind the motorcycle partly merged with that behind the cyclist. As a result, the size of the most intense under-pressure areas wrapping around the waist of the cyclist increased substantially, as did the size of the under-pressure area behind the cyclist and the overall absolute value of the pressure coefficient in the wake behind the cyclist. The larger under-pressure areas on the side were in line with the faster air speed around the sides of the cyclist in Fig. 6 .

Figure 8 displays contours of mean $C_{P}$ on the surface of the cyclist and motorcycle. While Fig. 8a,b only shows minor differences in terms of the positive $C_{P}$ values, Fig. $8 c$-f clearly shows larger under-pressure on the sides and torso of the cyclist as well as on the bicycle rear wheel due to the presence of the motorcycle.

Animations of the SAS-SST k- $\omega$ simulations are provided in (Supplementary Material 1, 2, 3, 4).

\section{Potential time gains}

The road cycling power model by Martin et al. [28] was employed to convert the drag change percentages in Figs. 3 and 4 to potential speed changes and potential time gains or losses:

$\mathrm{P}_{\mathrm{tot}}=\left(\mathrm{P}_{\mathrm{ad}}+\mathrm{P}_{\mathrm{rr}}+\mathrm{P}_{\mathrm{wb}}+\mathrm{P}_{\mathrm{pe}}+\mathrm{P}_{\mathrm{ke}}\right)\left(\frac{1}{\eta}\right)$

With $\mathrm{P}_{\text {tot }}$ the required power, $\mathrm{P}_{\mathrm{ad}}$ the power loss due to aerodynamic drag, $P_{r r}$ the power loss due to rolling resistance, $\mathrm{P}_{\mathrm{wb}}$ the power loss due to friction in the wheel bearings, $\mathrm{P}_{\mathrm{pe}}$ the power changes due to a change in potential energy and $\mathrm{P}_{\mathrm{ke}}$ the power changes due to changes in kinetic energy. The efficiency $\eta$ is that of the cyclist power transmission, associated to the friction in the drivetrain. For simplicity, we assumed level terrain and constant cycling speed so $\mathrm{P}_{\mathrm{pe}}=\mathrm{P}_{\mathrm{ke}}=0$, and no crosswind, headwind or tailwind. Equation (1) then becomes [28]:

$P_{t o t}=\left[0.5 \rho U^{3}\left(C_{D} A+F_{w}\right)+U C_{r r} m g+U(91+8.7 U) \cdot 10^{-3}\right] \frac{1}{\eta}$

We assumed the following parameter values: density $\rho=1.225 \mathrm{~kg} / \mathrm{m}^{3}$, reference isolated cyclist riding velocity $U=13 \mathrm{~m} / \mathrm{s}$, drag area $\mathrm{C}_{\mathrm{D}} \mathrm{A}=0.231 \mathrm{~m}^{2}$, wheel rotational drag area $\mathrm{F}_{\mathrm{w}}=0.001 \mathrm{~m}^{2}$, rolling resistance coefficient $\mathrm{C}_{\mathrm{rr}}=0.002$, cyclist-bicycle system mass $m=75 \mathrm{~kg}$, gravitational constant $g=9.81 \mathrm{~m} / \mathrm{s}^{2}$ and chain efficiency $\eta=0.97698$. Note that $13 \mathrm{~m} / \mathrm{s}$ was chosen instead of $15 \mathrm{~m} / \mathrm{s}$ as a more common speed for an isolated professional cyclist. This slight change in speed is expected not to influence the findings as the associated Reynolds effects on the percentages in Figs. 3, 4 are very limited. These values lead to $P_{\text {tot }}=342 \mathrm{~W}$ for the isolated cyclist riding at $13 \mathrm{~m} / \mathrm{s}$. To relate drag changes to speed changes and time gains or losses, it was assumed that the cyclist provided the same power $P_{\text {tot }}(=342 \mathrm{~W})$ when accompanied by the motorcycle. Table 1 presents the associated speed changes and the potential time gain or loss per $\mathrm{km}$ and per minute.

\section{Discussion}

The results of the CFD simulations can explain the drag changes in Figs. 3 and 4. Figure 3 shows an increased cyclist drag for parallel and slightly staggered 
Fig. 6 Results of SAS simulations for cyclist and motorcycle in parallel (left) versus isolated cyclist (right): contours of air speed in horizontal plane at $0.8 \mathrm{~m}$ height: $(\mathbf{a}, \mathbf{b})$ mean; $(\mathbf{c}-\mathbf{j})$ instantaneous at $0.12 \mathrm{~s}$ intervals

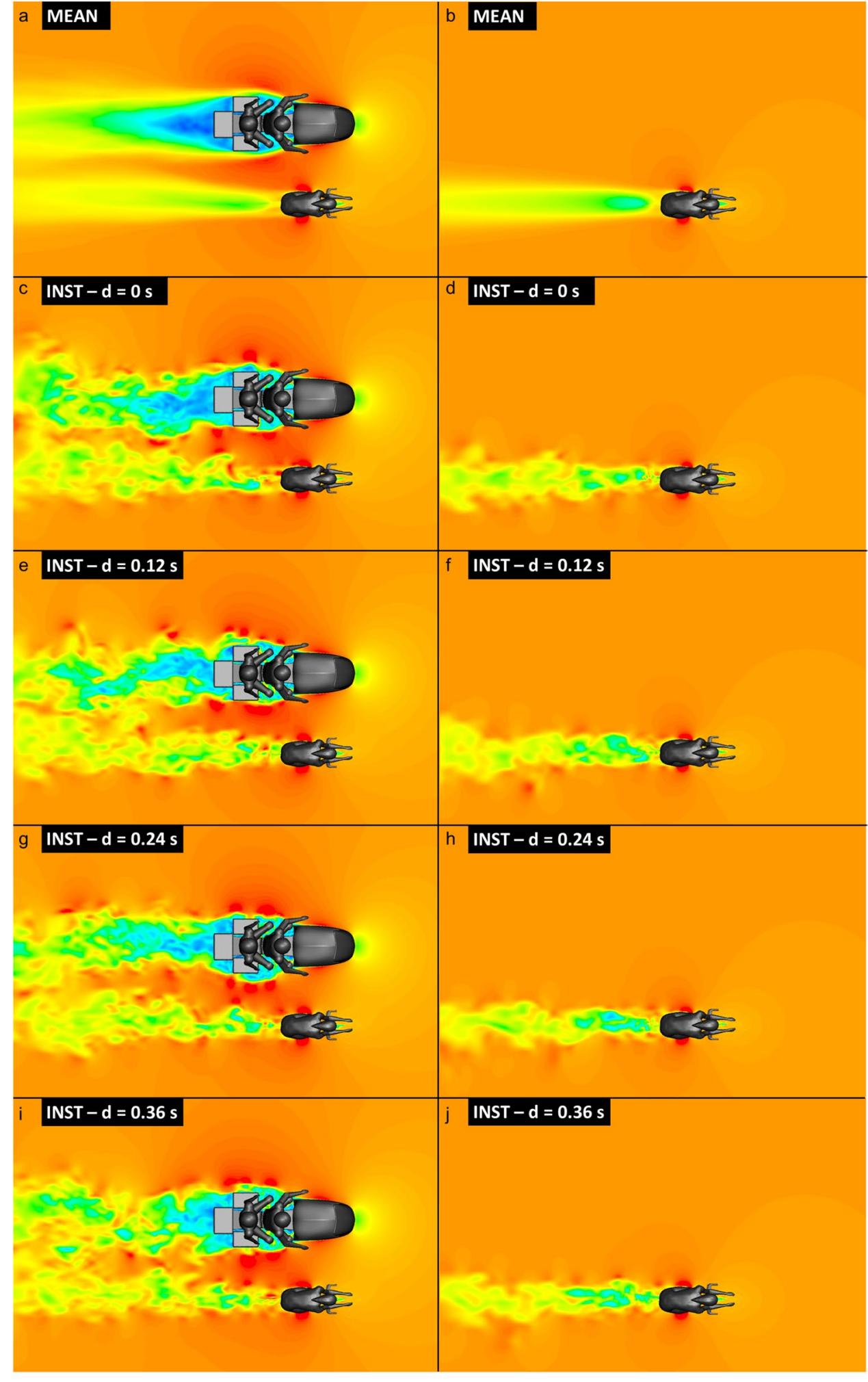

Velocity ( $\mathrm{m} / \mathrm{s})$

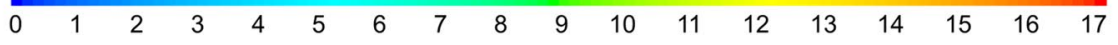


Fig. 7 Results of SAS simulations for cyclist and motorcycle in parallel versus isolated cyclist: contours of pressure coefficient $\mathrm{C}_{\mathrm{P}}$ in horizontal plane at $0.8 \mathrm{~m}$ height: $(\mathbf{a}-\mathbf{b})$ mean; $(\mathbf{c}-\mathbf{j})$ instantaneous at $0.12 \mathrm{~s}$ intervals

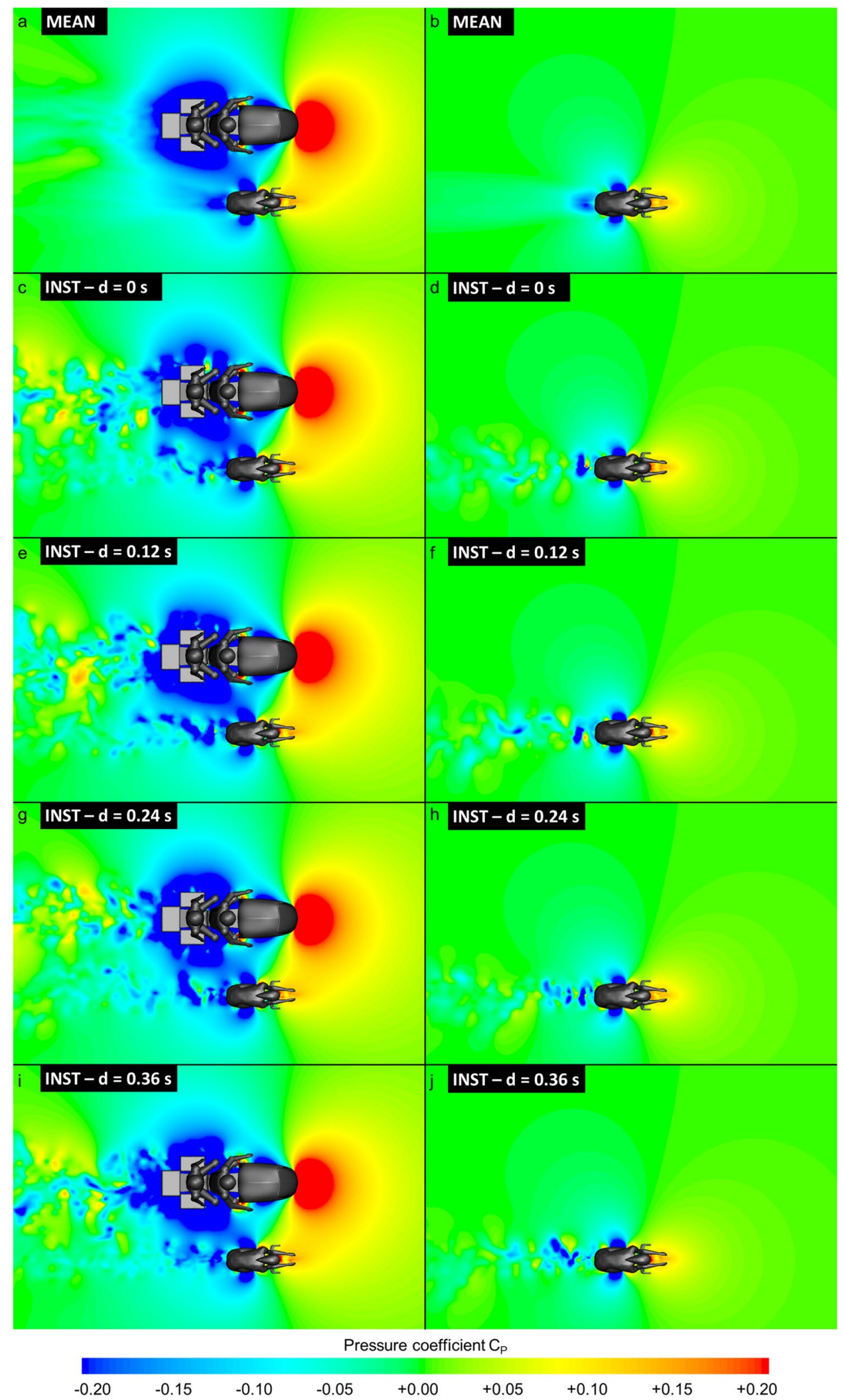

arrangements. Figures 6 and 8 show that the motorcycle increased the speed increment around the cyclist and the suction on the back of the cyclist. For the cyclist upstream of the motorcycle for $\Delta \mathrm{x}=-1.92 \mathrm{~m}$ and further, the cyclist experienced a drag decrease due to the subsonic upstream disturbance: the over-pressure area in front of 
Fig. 8 Results of SAS simulations: contours of mean pressure coefficient $\mathrm{C}_{\mathrm{P}}$ on the surfaces of cyclist and motorcycle, for the parallel arrangement versus the isolated cyclist

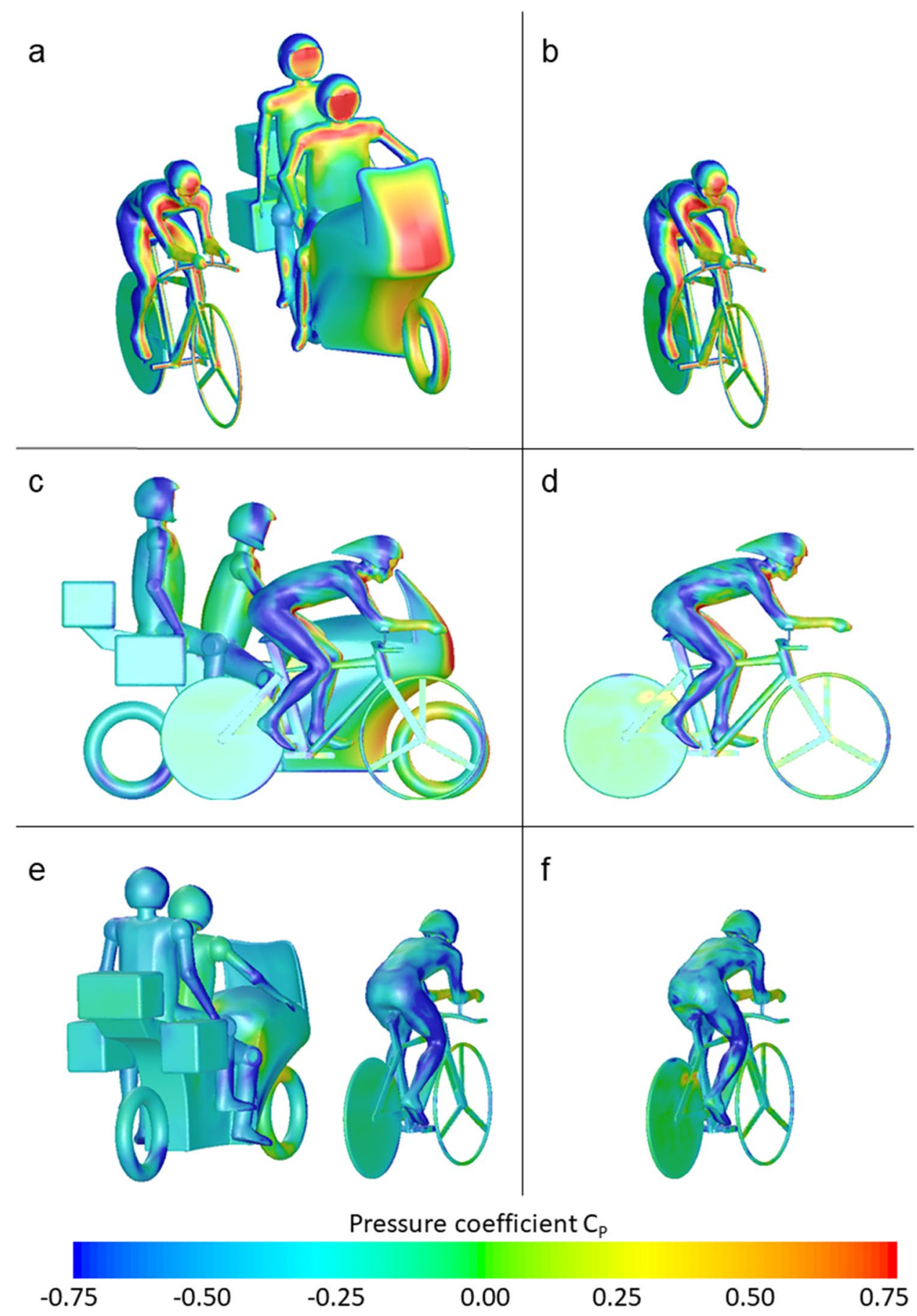

the motorcycle partly merged with the under-pressure area behind the cyclist, which reduced the suction on the back of the cyclist $[6,7,16]$. For the cyclist downstream of the motorcycle, for $\Delta \mathrm{x}=1.92 \mathrm{~m}$ and more, the cyclist experienced a drag decrease. This drag decrease occurred because the cyclist was partly positioned in the wake behind the motorcycle, which widened with increasing distance downstream, while simultaneously the velocity in the wake increased. These two effects seemed to balance each other yielding a fairly constant cyclist drag reduction from $\Delta \mathrm{x}=+2.88$ up to at least $+7.2 \mathrm{~m}$. Figure 4 shows a gradual reduction of the increased cyclist drag for larger $\Delta y$. This is attributed to the reduced effect of the motorcycle on the air speed around the cyclist and suction on the cyclist's back with increasing $\Delta y$.

Table 1 indicates that the potential time gains or losses are large, even for the moderate drag changes of about $2 \%$. As time 
Table 1 Potential changes in speed and time as a function of the change in drag

\begin{tabular}{|c|c|c|c|}
\hline Drag change & Speed change & $\begin{array}{l}\text { Time change } \\
\text { per km }\end{array}$ & $\begin{array}{l}\text { Time } \\
\text { change per } \\
\text { min }\end{array}$ \\
\hline$(\%)$ & $(\%)$ & (s) & (s) \\
\hline 12 & -3.6 & -2.88 & -2.16 \\
\hline 10 & -3.1 & -2.41 & -1.82 \\
\hline 8 & -2.5 & -1.94 & -1.48 \\
\hline 6 & -1.8 & -1.47 & -1.12 \\
\hline 4 & -1.2 & -0.98 & -0.76 \\
\hline 2 & -0.6 & -0.49 & -0.38 \\
\hline 0 & 0.0 & 0 & 0 \\
\hline-2 & 0.7 & 0.50 & 0.39 \\
\hline-4 & 1.3 & 1.01 & 0.80 \\
\hline
\end{tabular}

trials are sometimes won by fractions of a second, it is clear that a nearby motorcycle can influence the outcome of races.

Note that the precise values of drag reduction and time gains or losses in this paper pertain to the specific cyclist and motorcycle geometry tested and the parameter values chosen in Sect. 4. Crosswind, head wind or tail wind will evidently influence the drag and speed changes and the potential time gains and losses. When crosswind is present, the aerodynamic interaction between the cyclist and the motorcycle will be much more complicated and further research is required to study the associated wide range of possible scenarios.

Combined with our previous work on the aerodynamic impact of a nearby motorcycle on cyclist drag [7, 8], we now have a strong overall picture of the effect of a motorcycle, which can be in front, behind or to the side, on the aerodynamic drag of a cyclist. Each of these motorcycle positions has a clear effect that can change the outcome of a race. The present rules and guidelines of the UCI do not prevent these aerodynamic effects of nearby motorcycles. The most recent guidelines for "vehicle circulation in the race convoy" [9] only stipulate when and which motorcycles can enter the gaps between breakaway riders and the following riders in terms of time differences. Therefore, the UCI should consider modifying their rules and guidelines to prevent these undesired and unfair aerodynamic impacts. Nevertheless, solutions might not be straightforward given the wide range of duties of in-race motorcycles. A partial and potential solution could be the use of drones for television recording, to reduce the number of motorcycles in the race convoy to a minimum.

\section{Conclusion}

Building on our previous work that quantified the effect of a leading or trailing motorcycle on the drag of a cyclist, this paper analyzed the effect of a motorcycle in parallel and staggered arrangements with the cyclist. Wind tunnel tests for 32 different parallel and staggered cyclist-motorcycle arrangements were presented. It was shown that the parallel position leads to a substantial drag increase for the cyclist, in the range of 5 to about $10 \%$ for a lateral distance of 2 to $1 \mathrm{~m}$. The staggered position can lead to either a large drag increase or a moderate drag decrease of about $2 \%$ for most positions analyzed. For one of the parallel arrangements, CFD simulations were performed to provide insight in the reasons for the large drag increase. A cyclist power model was used to convert the drag changes into potential time gains or losses. Compared to a lone cyclist at $46.8 \mathrm{~km} / \mathrm{h}(13 \mathrm{~m} / \mathrm{s})$ on a level road in calm weather, the time loss by a drag increase of $10 \%, 4 \%$ and $-2 \%$ was $2.16,0.76 \mathrm{~s}$ and $-0.80 \mathrm{~s}$ per $\mathrm{km}$, respectively. These time differences are large enough to influence the outcome of cycling races.

Supplementary Information The online version contains supplementary material available at https://doi.org/10.1007/s12283-021-00344-3.

Acknowledgements We thank the technical support team of the Wind Tunnel Laboratory at the Department of the Built Environment at Eindhoven University of Technology: Ing. Jan Diepens, Geert-Jan Maas and Stan van Asten. This work was also sponsored by NWO Exacte en Natuurwetenschappen (Physical Sciences) for the use of supercomputer facilities, with financial support from the Nederlandse Organisatie voor Wetenschappelijk Onderzoek (Netherlands Organization for Scientific Research, NWO). We acknowledge the partnership with Ansys CFD.

Funding This work was unfunded work and performed as a selfdefined inter-university project by the researchers involved. The first author is an Associate Editor of Sports Engineering and had no involvement in the anonymous peer-review process.

\section{Declarations}

Conflict of interest The authors declare that they have no conflict of interest.

Open Access This article is licensed under a Creative Commons Attribution 4.0 International License, which permits use, sharing, adaptation, distribution and reproduction in any medium or format, as long as you give appropriate credit to the original author(s) and the source, provide a link to the Creative Commons licence, and indicate if changes were made. The images or other third party material in this article are included in the article's Creative Commons licence, unless indicated otherwise in a credit line to the material. If material is not included in the article's Creative Commons licence and your intended use is not permitted by statutory regulation or exceeds the permitted use, you will need to obtain permission directly from the copyright holder. To view a copy of this licence, visit http://creativecommons.org/licenses/by/4.0/.

\section{References}

1. Kyle CR, Burke ER (1984) Improving the racing bicycle. MechEng 1:34-45 
2. Grappe F, Candau R, Belli A, Rouillon JD (1997) Aerodynamic drag in field cycling. Ergonomics 40:1299-1311

3. Lukes RA, Chin SB, Haake SJ (2005) The understanding and development of cycling aerodynamics. Sport Eng 8:59-74

4. Crouch TN, Burton D, LaBry ZA, Blair KB (2017) Riding against the wind: a review of competition cycling aerodynamics. Sport Eng 20:81-110

5. Malizia F, Blocken B (2020) Bicycle aerodynamics: history, state of the art and future perspectives. J Wind EngIndAerodyn 200:104134

6. Blocken B, Toparlar Y (2015) A following car influences cyclist drag: CFD simulations and wind tunnel measurements. J Wind EngIndAerodyn 145:178-186

7. Blocken B, Toparlar Y, Andrianne T (2016) Aerodynamic benefit for a cyclist by a following motorcycle. J Wind EngIndAerodyn 155:1-10

8. Blocken B, Malizia F, van Druenen T, Gillmeier SG (2020) Aerodynamic benefit for a cyclist by drafting behind a motorcycle. Sports Eng 23:19

9. International Cycling Union (2017) Guidelines for vehicle circulation in the race convoy. Version February 2017. www.uci.org/ inside-uci/publications

10. Zdravkovich MM, Ashcroft MW, Chisholm SJ, Hicks N (1996) Effect of cyclist's posture and vicinity of another cyclist on aerodynamic drag. The Engineering of Sport (Haake (Ed.)), 21-28, Balkema, Rotterdam.

11. Barry N, Sheridan J, Burton D, Brown NAT (2014) The effect of spatial position on the aerodynamic interactions between cyclists. ProcEng 72:774-779

12. Gromke C, Ruck B (2021) Passenger car-induced lateral aerodynamic loads on cyclists during overtaking. J Wind EngIndAerodyn 209:104489

13. Eindhoven University of Technology (2017) You Tube channel; wind tunnel movie: https://www.youtube.com/watch?v=VEDn IUJQfs

14. Barlow JB, Rae WH, Pope A (1999) Low-speed wind tunnel testing. John Wiley and Sons

15. Blocken B, van DruenenT TY, Malizia F, Mannion P, Andrianne T, Marchal T, Maas GJ, Diepens J (2018) Aerodynamic drag in cycling pelotons: new insights by CFD simulation and wind tunnel testing. J Wind EngIndAerodyn 179:319-337

16. Blocken B, Defraeye T, Koninckx E, Carmeliet J, Hespel P (2013) CFD simulations of the aerodynamic drag of two drafting cyclists. Comput Fluids 71:435-445
17. Franke J, Hirsch C, Jensen AG, Krüs HW, Schatzmann M, Westbury PS, Miles SD, Wisse JA, Wright NG (2004) Recommendations on the use of CFD in wind engineering. Proc. Int. Conf. Urban Wind Engineering and Building Aerodynamics, (Ed. van Beeck JPAJ), COST Action C14, Impact of Wind and Storm on City Life Built Environment, von Karman Institute, Sint-Genesius-Rode, Belgium, pp. 5-7

18. Franke J, Hellsten A, Schlünzen H, Carissimo B (2007) Best practice guideline for the CFD simulation of flows in the urban environment. COST Action 5:732

19. Tominaga Y, Mochida A, Yoshie R, Kataoka H, Nozu T, Yoshikawa M, Shirasawa T (2008) AIJ guidelines for practical applications of CFD to pedestrian wind environment around buildings. J Wind EngIndAerodyn 96:1749-1761

20. Blocken B (2015) Computational Fluid Dynamics for urban physics: Importance, scales, possibilities, limitations and ten tips and tricks towards accurate and reliable simulations. Build Environ 91:219-245

21. Malizia F, Blocken B (2020) CFD simulations of an isolated cycling spoked wheel: impact of the ground and wheel/ground modeling. Eur J Mech B Fluids 82:21-38

22. Casey M, Wintergerste T (2000) Best practice guidelines ERCOFTAC special interest. ERCOFTAC

23. Tucker P, Mosquera A (2001) NAFEMS introduction to grid and mesh generation for CFD. NAFEMS CFD Work. Group.

24 Malizia F, Montazeri H, Blocken B (2019) CFD simulations of spoked wheel aerodynamics in cycling: impact of computational parameters. J Wind EngIndAerodyn 194:103988

25. Menter FR (1994) Two-equation eddy-viscosity turbulence models for engineering applications. AIAA J 32(8):1598-1605

26. Menter F, Egorov Y (2010) The scale-adaptive simulation method for unsteady turbulent flow predictions. Part 1: theory and model description. Flow Turb Combust 85:113-138

27. ANSYS Inc (2015) Ansys Fluent Theory Guide, Release 16.1. Canonsburg

28. Martin JC, Milliken DL, Cobb JE, McFadden KL, Coggan AR (1998) Validation of a mathematical model for road cycling. J ApplBiomech 14:276-291

Publisher's Note Springer Nature remains neutral with regard to jurisdictional claims in published maps and institutional affiliations. 